\title{
A Multiple Constraints Framework for Collaborative Learning Flow Orchestration
}

\author{
Kalpani Manathunga ${ }^{(凶)}$ and Davinia Hernández-Leo \\ ICT Department, Universitat Pompeu Fabra, Barcelona, Spain \\ \{kalpani.manathunga, davinia.hernandez\}@upf.edu
}

\begin{abstract}
Collaborative Learning Flow Patterns (e.g., Jigsaw) offer sound pedagogical strategies to foster fruitful social interactions among learners. The pedagogy behind the patterns involves a set of intrinsic constraints that need to be considered when orchestrating the learning flow. These constraints relate to the organization of the flow (e.g., Jigsaw pattern - a global problem is divided into sub-problems and a constraint is that there need to be at least one expert group working on each sub-problem) and group formation policies (e.g., groups solving the global problem need to have at least one member coming from a different previous expert group). Besides, characteristics of specific learning situations such as learners' profile and technological tools used provide additional parameters that can be considered as context-related extrinsic constraints relevant to the orchestration (e.g., heterogeneous groups depending on experience or interests). This paper proposes a constraint framework that considers different constraints for orchestration services enabling adaptive computation of orchestration aspects. Substantiation of the framework with a case study demonstrated the feasibility, usefulness and the expressiveness of the framework.
\end{abstract}

Keywords: CSCL $\cdot$ Collaborative Learning Flow Pattern(s) - Macro scripts · Jigsaw $\cdot$ Learning flow orchestration

\section{Introduction}

Collaborative learning supports knowledge construction and sharing by fostering effective social interactions [1]. Computer Supported Collaborative Learning (CSCL) is the field studying the role of technological support to mediate fruitful interactions resulting in effective learning. Research accumulated around CSCL have proposed and evaluated multiple pedagogical models (also called as macro-scripts intended to create quality interactions in collaborative learning [2, 3]) and implementation tools that engage learners in knowledge-intensive social interactions (conflict resolution, artifact co-design, mutual explanation, etc.) with identified significant learning outcomes [1, 4]. CSCL macro scripts specify required orchestration aspects such as group formation, role allocation and rotation, distribution of resources, using diverse collaboration spaces (shared boards, wikis, etc.), implementing communication and coordination mechanisms (flow control, group awareness, etc.) [5]. These orchestration aspects of a macro-script introduces set of constraints to shape up desired interactions whilst avoiding the risk of over-scripting [6]. Identification and adaptation of these constraints 
to design effective scripts are challenging and require proficiency [6-8]. Having weak constraints may lead to loose fruitful collaborations. On the contrary, rigid constraints spoil natural peer interaction mechanisms [2]. Hence, scripts should be flexible with no over-constraining in order to be adaptable in the learning context in operational CSCL. To facilitate flexible script design while avoiding over-scripting, it is important to understand the notions of intrinsic and extrinsic constraints [2]. A more detailed explanation of intrinsic and extrinsic constraints is provided in Sect. 2.

Collaborative Learning Flow Patterns (CLFPs) like Jigsaw, Pyramid capture the essence of well-known techniques in macro scripts to produce potentially effective collaborations [3]. These patterns introduce set of conditions namely intrinsic constraints to be met while shaping up the desired collaborations [2]. Previous work in the field $[9,10]$ had demonstrated extensive knowledge in extracting such constraints, especially in small classroom contexts. Yet more scrutinized insight is required when aggregating CLFP based collaborative learning in large learning contexts [11] like Massive Open Online Courses where learner community grows dynamically and constant modifications of pre-created scripts designs are required. Discontinuous participation and varied learner behavior within such open learning environments require redefining orchestration mechanisms frequently. These concerns raise need to recognize flexible aspects within macro scripts, which types of constraints can be applied and how those can be manipulated. Specifically this contribution proposes a multiple constraint framework to facilitate effective CSCL script design introducing essential parameters. The technological viability of the framework is then evaluated with an automated orchestration service applied upon real-class case study. Signal Orchestration System (SOS) [12], an implementation of the framework, is a web-based CLFP service provider that facilitates configuring automatic orchestration of collaborative activities across different contexts: physical spaces and course platforms. SOS orchestration services allow adaptive computation of orchestration configurations accommodating dynamic changes like absentees, dropping out students providing dynamic modifications to pre-created CSCL scripts.

Remaining content of the manuscript is spelled out as; Sect. 2 explaining the principles of the framework and its main components presented as two models to accommodate intrinsic and extrinsic constraints. The section is complemented with a literature analysis across existing proposals. Section 3 illustrates a case study including the framework realization along with experimental details followed by concluding remarks and future research directions.

\section{Multiple Constraints Framework}

Macro scripts, generally used to structure a collaborative activity to foster intended interactions among learners [2]. Hence, generating effective scripts for CSCL is time consuming, challenging and require expertise knowledge [7, 8, 13]; these concerns become exponential when a large class is considered. Therefore researchers' interest had drawn for CSCL scripting [1, 3] and computer supported orchestration mechanisms [14] by identifying and modelling both practitioner and participant constraints. Intrinsic constraints are guarded by the pedagogical rationale behind the script and extrinsic 
constraints can be induced from diverse sources such as educational context, technological factors or even from arbitrary decisions [2]. In CLFP macro-scripts, set of intrinsic pedagogical constraints bound to the core of the pattern pedagogy are already defined [3,9] to be considered when designing the script (see Table 1). Contrary, characteristics of specific learning situations, such as learners' profiles, their interests and technological tools supporting the activities (course platforms, social media) also provide additional parameters that can be exploited as constraints from a pedagogical perspective (extrinsic). Therefore further articulation of the role of context-related extrinsic constraints and its operational articulation with intrinsic constraints are critical. Automatic or semi-automatic orchestration systems supporting teachers in script design should implement algorithms that require considering both types of constraints. Furthermore in real scenarios constraints need to be considered with priorities for more realistic constraint computations. Intrinsic basis is critical since it lays the fundamentals; if these are not satisfied, the underlying pedagogy is violated; hence those should be considered as "hard" constraints. Extrinsic or context-related constraints are complementary that are preferred to be implied as those "soft" constraints add beneficial value resulting in meaningful interactions. Articulation of hard and soft constraints needs to be clearly distinguished and applied since it defines the flexibility of the macro-script. These set the rules on the modifiability aspects within the script [2]. Modelling these multiple constraints in a constraint-framework expressing parameters of hard and soft constraints is equally important for the implementation of orchestration services which can be easily adapted by practitioners when enacting collaborative activities.

Table 1. Jigsaw and Pyramid patterns hard constraints

\begin{tabular}{|c|c|}
\hline Jigsaw pattern & Pyramid pattern \\
\hline $\begin{array}{l}\text { Relates to a situation where several small } \\
\text { groups of students ('Jigsaw' groups) each } \\
\text { trying to solve a complex problem that can } \\
\text { be divided into sub-problems. Each group } \\
\text { participant studies one sub-problem } \\
\text { individually. Participants from different } \\
\text { jigsaw groups meet up in temporary } \\
\text { 'Expert' groups to exchange ideas about } \\
\text { their common sub-problems. Finally, } \\
\text { participants return back to their jigsaw } \\
\text { groups to share the knowledge and solve } \\
\text { the global problem. This pattern fosters } \\
\text { individual accountability and personal } \\
\text { responsibility. }\end{array}$ & $\begin{array}{l}\text { Starts individually or forming initial small } \\
\text { groups to study a common problem and } \\
\text { propose initial solutions. Then, students } \\
\text { are grouped (usually pairs) to compare and } \\
\text { discuss their proposals and, finally, } \\
\text { propose a new shared solution. Students } \\
\text { are guided so that the groups join with new } \\
\text { groups to form larger groups in order to } \\
\text { generate new agreed proposals. Likewise } \\
\text { this will iterate till the whole group reaches } \\
\text { upon a global consensus. This pattern } \\
\text { fosters positive interdependence and } \\
\text { individual accountability. }\end{array}$ \\
\hline
\end{tabular}

\subsection{Model of Collaborative Learning Flow Pattern(s) Hard Constraints}

Hard constraints are strictly bound with the pedagogical design of the script; hence can be considered as the core of the script design [2, 9]. In pattern based macro scripting, the pattern definition sets the rationale for the intended orchestration of the collaborative activity (Table 1 ). 
These hard constraints set the boundary of script adaptability in a particular CLFP in order to not to kill the guarding pedagogical rationale. For instance, in Jigsaw pattern, "each group must have at least one expert who had studied each sub task of the activity to collaboratively share knowledge". An analysis of related work [9, 10] on extraction of intrinsic constraints of CLFPs and additional revision of the CLFPs have led to formulate hard constraint conceptual model (Fig. 1). Pattern elements (denoted by white rectangles) and parameters (denoted by ash rectangles) are important to be considered when designing the script. As an example, a Jigsaw activity is defined by three specific phases as "Individual", "Expert" and "Jigsaw" phases (Table 1) with a task (that has number of sub tasks) that include specific number of groups proportionate to the number of sub tasks. Any pattern has a number of phases defined by its definition or derived according to other variables like the number of participants for the activity. These phases have a problem (either one task or set of sub tasks) to be solved and a bunch of groups to solve tasks. If problem $>1$, number of problems should be specified. For some CLFPs, problems may be presented with set of roles inherited which is represented with the number of roles as a parameter.

Most of the CLFPs have a unique definition for grouping within phases. A group has a size specifying a minimum (and sometimes the maximum) number of participants when composing the group. Generally the number of possible groups is also defined with the pedagogical definition of CLFPs along with different group formation policies. Furthermore roles are defined according to certain policies (Group policy) such as appointing team leader based on previous experiences or highest marks or randomly where every odd number becomes a problem-solver and even number becomes a

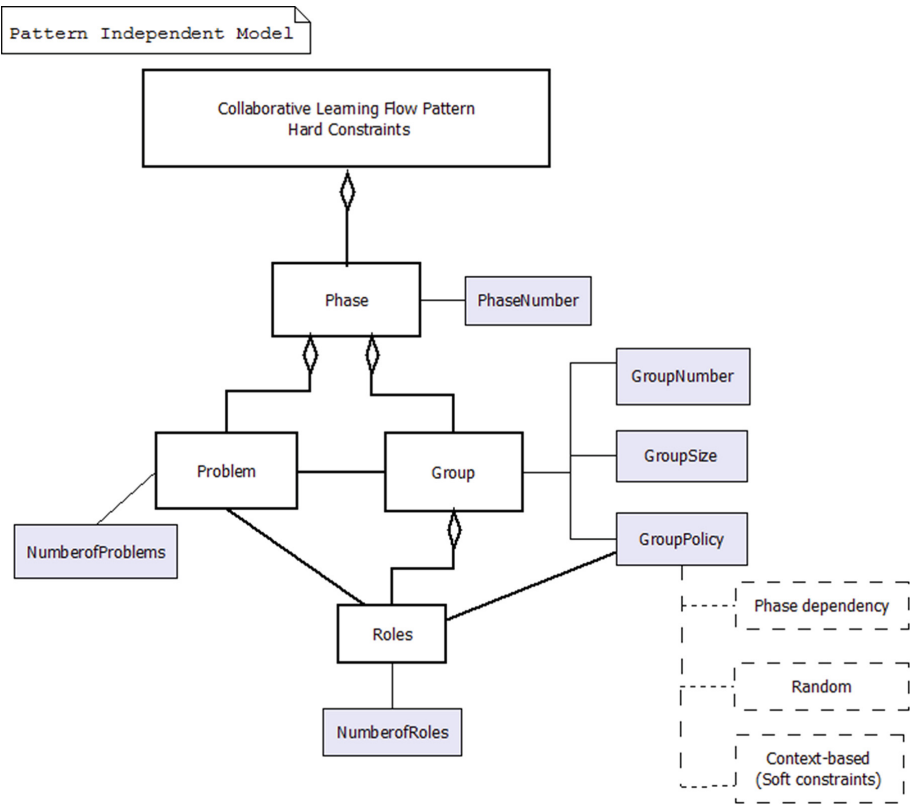

Fig. 1. Conceptual model of CLFP hard constraints 
listener. Therefore different elements (denoted by dashed rectangles in Fig. 1) can be attached with group policy parameter like phase dependency when group formation technique depends on the behavior of the previous phase, completely random or considering practical criteria without pedagogical rationale (e.g., alphabetical order in names). Further context-based elements or soft constraints can be the value for group formation policy which is extensively explored in the next subsection through soft constraint model.

\subsection{Generic Model for Soft Constraints}

As education contexts generate abundant elements that can be considered when designing collaborative activities causing further fruitful interactions, a soft constraint model is suggested to make the framework more comprehensive. Soft constraints define limitations in a macro-script that are "preferred to be satisfied" [2] and do not violate any pedagogical perspective, if not satisfied; hence these are rather flexible in terms of constraint satisfaction. Figure 2 illustrates a conceptual model that elaborates potential sources to retrieve soft constraints within a given learning scenario. Parameters of learner profile such as personal details (marks, level of education, country of origin) or individual learning style or previous experiences or interests (skills) are used as group formation policies [8, 14]. With the advent of open APIs exposed by different social media such as Facebook, Twitter, LinkedIn gives an opportunity for educational tool developers to extract public profile details of the learner [15]. Hence, different social media parameters such as number of connections, friendship, preferences, number of likes or tweets, recommendations that had been received can be accepted as soft constraints. Learning setting can be defined in different perspectives such as the infrastructure used like hardware devices or other software tools or the location settings like co-located vs. distant or being in a specific location. Further even individual availability can be vital especially in distance learning contexts [8].

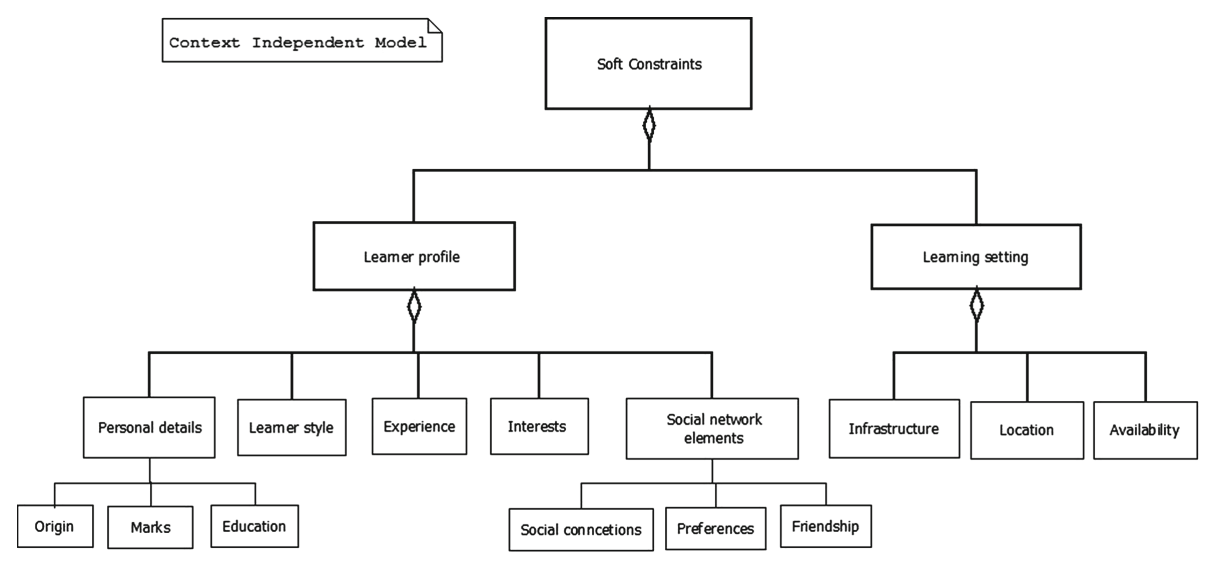

Fig. 2. Generic model for soft constraints 
Table 2 demonstrates a literature analysis of various parameters that had been considered in previous work to implement collaborative activities. We studied their approaches and parameters apprehended. The analysis provided insights to what extent hard or soft constraints had been considered and how their approaches are compatible and expressed within our proposed framework (highlighted in bold letters).

Table 2. Constraints based CL studies (analysis \& comparison with proposed framework)

\begin{tabular}{|c|c|c|}
\hline Article & Approach/Methodology & Parameters considered \\
\hline $\begin{array}{l}\text { Spoelstra, van } \\
\text { Rosmalen, } \\
\text { Houtmans \& } \\
\text { Sloep [8] }\end{array}$ & $\begin{array}{l}\text { Based on a survey, learners are } \\
\text { allocated in Project-based } \\
\text { Learning scenarios. Learner age, } \\
\text { gender, Big5 personality test, } \\
\text { knowledge and work preferences } \\
\text { like language, no of hours, } \\
\text { availability are concerned. } \\
\text { Formed } 3 \text { types of teams: } \\
\text { productive, creative and learning } \\
\text { teams which were validated by } \\
\text { teachers. }\end{array}$ & $\begin{array}{l}\text { Conscientiousness } \\
\text { (learner style) } \\
\text { Knowledge (experience) } \\
\text { Demographics (origin) } \\
\text { Preferred time slots } \\
\text { (availability) }\end{array}$ \\
\hline $\begin{array}{l}\text { Sun \& Shen } \\
{[14]}\end{array}$ & $\begin{array}{l}\text { Using learning styles and genetic } \\
\text { algorithm, Jigsaw CLFP is } \\
\text { applied. Social features of } \\
\text { learners had been considered. An } \\
\text { extended service structure with } \\
\text { many components (scheduler, } \\
\text { inference engine and monitoring } \\
\text { service) and also facilitates cloud } \\
\text { hosted MOODLE and mobile } \\
\text { access. }\end{array}$ & $\begin{array}{l}\text { Jigsaw pattern constraints (hard } \\
\text { constraints) } \\
\text { Learning style (learner style) } \\
\text { Comprehensive teamwork skills } \\
\text { (experience or interests) }\end{array}$ \\
\hline $\begin{array}{l}\text { Ounnas, Davis \& } \\
\text { Millard [13] }\end{array}$ & $\begin{array}{l}\text { When student name, gender and } \\
\text { the learner roles are given as the } \\
\text { knowledge to a predicate solver, } \\
\text { a group model is generated } \\
\text { considering both strong and } \\
\text { weak constraints defined by the } \\
\text { teacher. Algorithm ensures } \\
\text { maximum allocation leaving no } \\
\text { orphans. }\end{array}$ & $\begin{array}{l}\text { Learner styles, preferred } \\
\text { modules, collaborators, etc. } \\
\text { (personal details and learner } \\
\text { style) } \\
\text { Past track record of student } \\
\text { (marks or experience) }\end{array}$ \\
\hline $\begin{array}{l}\text { Inaba \& Ando } \\
{[16]}\end{array}$ & $\begin{array}{l}\text { Groups are formed based on } \\
\text { pre-test results. CL orchestration } \\
\text { is provided with "reciprocal } \\
\text { schema" script in which learners } \\
\text { take turns in different roles } \\
\text { (preparer, answerer, grader) }\end{array}$ & $\begin{array}{l}\text { Role assignment (hard } \\
\text { constraints) } \\
\text { Same academic level based on } \\
\text { marks obtained (marks) }\end{array}$ \\
\hline
\end{tabular}


Table 2. (Continued)

\begin{tabular}{|c|c|c|}
\hline Article & Approach/Methodology & Parameters considered \\
\hline $\begin{array}{l}\text { Agrawal, } \\
\text { Golshan \& } \\
\text { Terzi [17] }\end{array}$ & $\begin{array}{l}\text { Uses clustering algorithm to group } \\
\text { criteria being the ability in } \\
\text { subject. Algorithm groups } \\
\text { students with similar capabilities } \\
\text { to maximize team performance, } \\
\text { e.g.: highest ability leaders are } \\
\text { grouped with highest ability } \\
\text { followers }\end{array}$ & Ability over the subject (marks) \\
\hline Sinha [15] & $\begin{array}{l}\text { A MOOC has been considered as a } \\
\text { social network and applied } \\
\text { Social Network Analysis to form } \\
\text { groups. Only performed an } \\
\text { analysis of an existing } \\
\text { Coursera MOOC to construct a } \\
\text { social network graph of } 3848 \\
\text { edges acquired from discussion } \\
\text { forums }\end{array}$ & $\begin{array}{l}\text { Profile information like interests } \\
\quad \text { (interests) } \\
\text { Student implicit skills like social } \\
\text { positioning within discussions } \\
\text { (Social connections or } \\
\text { Friendship) }\end{array}$ \\
\hline
\end{tabular}

\section{Jigsaw Pattern Based Case Study}

In this section, a case study is explained illustrating feasible implementation of the framework and its usefulness. Jigsaw CLFP (see Table 1) was adhered and the constraints for the collaborative activity were devised following the proposed framework along with technological orchestration support (Table 3). Signal Orchestration System (SOS) [12], a prototype implementation of the Jigsaw service with signaling mechanism to notify orchestrations aspects (group formation, phase changes and resource allocation) using wearable or smartphones has been used in an authentic educational scenario. The activity was enacted in an Art class of a Catalan High school with 19 students (age: 13-15). Students and the teacher had previous experience of using Moodle. Teacher designed the activity using SOS which allocated students to Expert and Jigsaw phases with respective orchestration signals. List of students was exported to SOS via a Moodle plug-in embedded with SOS and two different personal devices (9 wearable devices and 9 smartphones) were used to retrieve orchestration signals. Five color lamps were used to identify the group location during phase-switching (Fig. 3). 5 Expert groups were formed to study different art tendencies: Art-deco, Futurism, Modernism, Recycle and Pop-Art and they were allocated into 3 Jigsaw groups representing Industrial, Graphic \& Interiors. Jigsaw groups uploaded their final answers to the respective Moodle link. As shown in Table 3, apart from the hard constraints, soft constraints were also applied when forming expert groups (homogenous groups by the device used-wearable or smartphone-in order to observe which device type was easier for them to recognize the signal received). This distribution of devices was only for experimental purposes and there were no pedagogical effects/constraints over the 
Table 3. Constraints considered in the adaptive orchestration service based on Jigsaw CLFP

\begin{tabular}{|c|c|c|c|}
\hline $\begin{array}{l}\text { Jigsaw } \\
\text { phase }\end{array}$ & Constraint & Constraints & Description \\
\hline \multirow[t]{3}{*}{$\begin{array}{l}\text { Phase } 1 \\
\quad \text { (Individual) } \\
\text { Study given } \\
\text { sub- } \\
\text { problem } \\
\text { individually }\end{array}$} & \multirow[t]{3}{*}{ Hard } & GroupSize_1 $>=1$ & $\begin{array}{l}\text { Each group can } \\
\text { consist of an } \\
\text { individual or in } \\
\text { small-sized } \\
\text { groups }\end{array}$ \\
\hline & & GroupNumber_1 $>=2$ & $\begin{array}{l}\text { There must be at } \\
\text { least two groups } \\
\text { for collaboration }\end{array}$ \\
\hline & & $2<=$ NumberofProblems_ $1<=\mathrm{P} / 2$ & $\begin{array}{l}\text { Should be at least } 2 \\
\text { sub-problems but } \\
\text { no more than half } \\
\text { the number of } \\
\text { participants to } \\
\text { allow } \\
\text { collaboration in } \\
\text { expert groups }\end{array}$ \\
\hline \multirow{5}{*}{$\begin{array}{l}\text { Phase } 2 \\
\text { (Expert) } \\
\text { Students } \\
\text { with the } \\
\text { same sub } \\
\text { problem are } \\
\text { grouped for } \\
\text { collaboration }\end{array}$} & \multirow[t]{4}{*}{ Hard } & $\begin{array}{l}\text { NumberofProblems_2 } \\
\quad=\text { NumberofProblems_1 }\end{array}$ & $\begin{array}{l}\text { Same sub problems } \\
\text { like in the } \\
\text { individual phase }\end{array}$ \\
\hline & & GroupSize_2 $>=2$ & $\begin{array}{l}\text { There must be at } \\
\text { least } 2 \\
\text { participants in } \\
\text { expert group to } \\
\text { allow } \\
\text { collaboration }\end{array}$ \\
\hline & & GroupNumber_2 => NumberofProblems_2 & $\begin{array}{l}\text { There must be at } \\
\text { least one group of } \\
\text { experts for each } \\
\text { sub-problem }\end{array}$ \\
\hline & & $\begin{array}{l}\text { GroupPolicy_2 }=\text { Having same problem as } \\
\text { in Phase } 1\end{array}$ & $\begin{array}{l}\text { Experts with same } \\
\text { sub-task/problem } \\
\text { given in phase } 1 \\
\text { should be } \\
\text { grouped together }\end{array}$ \\
\hline & Soft & $\begin{array}{l}\text { GroupPolicy_2 = Homogenous (either } \\
\text { device1/device2) }\end{array}$ & $\begin{array}{l}\text { Homogenous } \\
\text { groups using the } \\
\text { same device are } \\
\text { grouped together } \\
\text { within context }\end{array}$ \\
\hline $\begin{array}{l}\text { Phase } 3 \\
\text { (Jigsaw) } \\
\text { Different } \\
\text { experts are } \\
\text { grouped to }\end{array}$ & Hard & GroupSize_3 >=NumberofProblems_1 & $\begin{array}{l}\text { The group sizes } \\
\text { must be large } \\
\text { enough to gather } \\
\text { experts from all } \\
\text { areas }\end{array}$ \\
\hline
\end{tabular}


Table 3. (Continued)

\begin{tabular}{|c|c|c|c|}
\hline $\begin{array}{l}\text { Jigsaw } \\
\text { phase }\end{array}$ & Constraint & Constraints & Description \\
\hline \multirow[t]{3}{*}{$\begin{array}{l}\text { solve the } \\
\text { global task. }\end{array}$} & & GroupNumber_3 <= P/GroupSize_3 & $\begin{array}{l}\text { The number of } \\
\text { jigsaw groups } \\
\text { must be in } \\
\text { accordance with } \\
\text { the number of } \\
\text { experts of each } \\
\text { area }\end{array}$ \\
\hline & & NumberofProblems_3 = 1 & $\begin{array}{l}\text { Global } \\
\text { task/problem } \\
\text { should be solved } \\
\text { in Jigsaw phase } \\
\text { with experts from } \\
\text { all areas }\end{array}$ \\
\hline & & $\begin{array}{l}\text { GroupPolicy_3 = Each jigsaw group } \\
\text { having at least one expert }\end{array}$ & $\begin{array}{l}\text { Jigsaw groups must } \\
\text { consist of at least } \\
\text { one expert } \\
\text { representing each } \\
\text { sub-problem }\end{array}$ \\
\hline
\end{tabular}

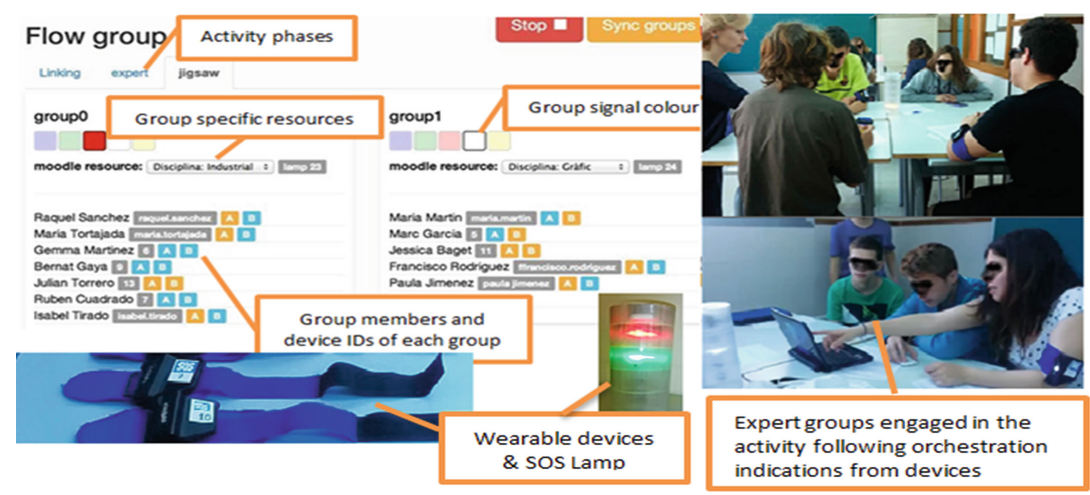

Fig. 3. SOS orchestration configurations, devices and activity enactment at different phases

experiment. In the table, "P" denotes the total number of participants and when $\mathrm{P}$ is known, the constraint values could be derived accordingly.

When grouping students into Expert and Jigsaw groups, it was compulsorily satisfied that at least one Expert member must be present in each Jigsaw group by the grouping service. Every Jigsaw group included Experts from every sub task and some groups had more than one Expert from the same sub task. In addition to phase constraints, students were allocated to 5 sub tasks, i.e., more than 2 sub tasks but less than half the number of total participants allowing each sub task to have one corresponding Expert group. Figure 3 shows sample screen devised when enacting Jigsaw phase in 
SOS and how students were engaged in the activity at Expert and Jigsaw phases. These SOS suggested orchestration arrangements can be modified according to teacher's preference on-the-fly (e.g.: group members, resources, signal colors).

\section{Conclusion}

Diverse learning contexts and their parameters introduce different constraints to enrich learner collaborations. These suggestions demand application of further constraints within macro-scripts to fine-tune orchestration aspects (e.g., group formation, resource allocation) based on diverse constraints such as availability, time-zones, etc. Furthermore CSCL scripts need to be flexible within learning context; neither being over-constrained nor killing natural interaction mechanisms. Careful identification of intrinsic and extrinsic constraints without harming the governing pedagogical rationale is equally important during the design stage. Hence the design of effective scripts requires careful thought-out and expertise knowledge.

This article presents holistic conceptual framework illustrating the derivation of intrinsic and extrinsic constraints including respective parameters to be considered in a given CLFP that can emerge efficient interactions in a collaborative activity. The substantiation of the previous work also claims that the models comply with the requirements that any automatic or semi-automatic orchestration service should adhere. Jigsaw pattern based case study illustrates constraint extraction and technological application in an authentic class scenario. Further, adherence of diverse constraints guarantees the expressiveness and usability of the proposed framework. Signal Orchestration System, prototype implementation based on the framework enabled automatic orchestration services ensuring feasibility of the framework. Learning technologists can consider the proposed framework when designing more practical technological tools appropriate for collaborative learning.

As future research directions, diverse experimental studies would be carried out in authentic learning contexts including Massive Open Online Courses satisfying different types of requirements and constraints emerging from these contexts. Relevant technological tools required for such experimental settings are being implemented complying with the framework. Such technology mediated orchestration services based on collaborative pedagogical patterns will be then utilized within authentic experimental studies to support practitioners to configure effective CSCL scripts and enact in real class scenarios fostering fruitful knowledge-intensive interactions.

Acknowledgements. Special thanks to participants from Escola de Santboi, Spain. This work has been partially funded by the Spanish Ministry of Economy and Competitiveness (TIN2014-53199-C3-3-R; MDM-2015-0502).

\section{References}

1. Dillenbourg, P.: What do you mean by 'collaborative learning'? In: Collaborative Learning: Cognitive and Computational Approaches. Elsevier Science, New York (1999) 
2. Dillenbourg, P., Tchounikine, P.: Flexibility in macro-scripts for CSCL. J. Comput. Assist. Learn. 23(1), 1-13 (2007)

3. Hernández-Leo, D., Villasclaras-Fernández, E.D., Asensio-Pérez, J.I., Dimitriadis, Y., Jorrín-Abellán, I.M., Ruiz-Requies, I., Rubia-Avi, B.: COLLAGE: a collaborative learning design editor based on patterns. J. Educ. Technol. Soc. 9, 58-71 (2006)

4. Stahl, G., Koschmann, T., Suthers, D.: Computer-supported collaborative learning: an historical perspective. In: Cambridge Handbook of the Learning Sciences, pp. 409-426 (2006)

5. Kobbe, L., Weinberger, A., Dillenbourg, P., Harrer, A., Hämäläinen, R., Häkkinen, P., Fischer, F.: Specifying computer-supported collaboration scripts. Int. J. Comput. Support. Collaborative Learn. 2, 211-224 (2007)

6. Dillenbourg, P.: Over-scripting CSCL: The risks of blending collaborative learning with instructional design. Three worlds CSCL Can we Support CSCL? Open University of Netherlands, pp. 61-91 (2002)

7. Hernández-Leo, D., Asensio-p, J.I., Dimitriadis, Y., Villasclaras-fern, E.D.: Generating CSCL scripts. from a conceptual model of pattern languages to the design of real scripts. In: Goodyear, P., Retalis, S. (eds.) Technology-Enhanced Learning, Design Patterns and Pattern Languages. Series Technology Enhanced Learning, pp. 49-64. Sense Publishers, Rotterdam (2010)

8. Spoelstra, H., van Rosmalen, P., Houtmans, T., Sloep, P.: Team formation instruments to enhance learner interactions in open learning environments. Comput. Hum. Behav. 45, 1120 (2015)

9. Pérez-Sanagustín, M., Burgos, J., Hernández-Leo, D., Blat, J.: CLFP intrinsic constraints-based group management of blended learning situations. In: Daradoumis, T., Caballé, S., Juan, A.A., Xhafa, F. (eds.) Technology Enhanced Systems and Adaptation Methods for Collaborative Learning Support. Series Studies in Computational Intelligence, vol. 350, pp. 115-133. Springer, Heidelberg (2011)

10. Rodríguez-Triana, M.J.: Linking scripting and monitoring in blended CSCL Linking scripting \& monitoring support in blended CSCL scenarios. Ph.D. dissertation, ETSI Telecommunication, UVA, Valladolid, Spain (2014)

11. Manathunga, K., Hernández-leo, D.: Has research on collaborative learning technologies addressed massiveness? a literature review. J. Educ. Technol. Soc. 18(4), 357-370 (2015)

12. Hernández-leo, D., Nieves, R., Arroyo, E., Rosales, A., Melero, J., Blat, J.: SOS : orchestrating collaborative activities across digital and physical spaces using wearable signaling devices. J. Univ. Comput. Sci. 18(15), 2165-2186 (2012)

13. Ounnas, A., Davis, H.C., Millard, D.E.: A framework for semantic group formation in education. J. Educ. Technol. Soc. 12(4), 43-55 (2009)

14. Sun, G., Shen, J.: Facilitating social collaboration in mobile cloud-based learning: a teamwork as a service (TaaS) approach. IEEE Trans. Learn. Technol. 7(3), 207-220 (2014)

15. Sinha, T.: Together we stand, together we fall, together we win: dynamic team formation in massive open online courses. In: Fifth International Conference on the Applications of Digital Information and Web Technologies, pp. 107-112 (2014)

16. Inaba, T., Ando, K.: Development and assessment of CSCL system for large classrooms using collaborative script. In: eLmL 2014: The Sixth International Conference on Mobile, Hybrid and Online Learning, Spain, pp. 14-21 (2014)

17. Agrawal, R., Golshan, B., Terzi, E.: Forming beneficial teams of students in massive online classes. In: First ACM Conference on Learning @ Scale, Atlanta, pp. 155-156 (2014) 